\title{
Infectious complications in chronic lymphocytic leukemia- a retrospective analysis: single institution experience
}

\author{
L. DEMITROVICOVA ${ }^{1, *}$, E. MIKUSKOVA ${ }^{1}$, I. ORAVCOVA ${ }^{1}$, S. CINGELOVA ${ }^{1}$, L. DRGONA ${ }^{1}$, B. MLADOSIEVICOVA ${ }^{2}$ \\ ${ }^{1}$ National Cancer Institute, Oncohematology Clinic, Department of Oncohematology II, Bratislava, Slovakia, ${ }^{2}$ Institute of Pathological Physiology, \\ Faculty of Medicine, Comenius University, Bratislava, Slovakia
}

*Correspondence: mdemitrovic@gmail.com

Received November 30, 2016 / Accepted January 19, 2017

\begin{abstract}
The aim of this study was to evaluate the incidence of a variety of infectious complications in patients with CLL regarding the duration of CLL and the type of treatment. We present the retrospective analysis of patients with CLL treated at our institution in years 2004-2016. We collected data about the type of infection, pathogenes, treatment and severity of infections surpassed in connection with administration treatment. In the study one hundred and ten patients were evaluated. The average age of patients was 61.7 years (range 34.5-91.9 years). Fludarabine was the most widely used regimen, followed by bendamustine and alemtuzumab. We recorded 393 episodes of infections, of which 114 (29\%) were severe and life threatening of degree 3-5, and $279(71 \%)$ of degree 2 . The most common infections were the upper respiratory tract infections together with sinusitis (45.03\%), pneumonia (26.20\%), CMV reactivation occured in $8.14 \%$, infections of the skin was in $7.6 \%$. Most infections have occurred with the administration of monoclonal antibody alemtuzumab, these patients were at significantly higher risk of infection [RR 2.59 (1.30 to 5.17)] than patients receiving obinutuzumab [RR 0.63 (0.48 to 0.82)] ( $\mathrm{p}=0.0001)$. On the contrary, the safety profile of BCR signaling pathway inhibitors was very acceptable [RR $1.17(0.70-1.96)]$. The number of infections have decreased during the first 12 months of treatment with ibrutinib. In the study group we recorded 19 deaths, $8(7.27 \%)$ of them were of infectious etiology. The risk of infectious complications is lifelong in patients with CLL, it can be minimized by early detection and aggressive management. Novel targeted agents used in therapy of CLL have a good safety profile, even the risk of infection is decreased during administration.
\end{abstract}

Key words: chronic lymphocytic leukemia, infectious complications, inhibitors of BCR signaling, monoclonal antibodies

According to the literature data infectious mortality ranges between $25-50 \%$ in patients with chronic lymphocytic leukemia (CLL) [1]. The pathogenesis of these complications is related to immune defects inherent to the primary disease as well as to therapy- related immunosuppression. The defect in humoral and cellular immunity and neutropenia of different degrees are characteristic for patients with CLL and it depends on bone marrow infiltration by the underlying disease. This defect of immunity is worsening with duration of the disease. Hypogammaglobulinaemia occurs in almost all patients with CLL, it is not reversible also in achieving complete remission and it is associated with frequent bacterial infections in patients with CLL. Disorders of cellular immunity, which are of a broad spectrum,are present in a more advanced stage of CLL and they contribute to the development of opportunistic infections viral, fungal, mycobacterial and pneumocystis infections [2].
The spectrum of infections depends on the type of therapy. Patients treated with alkylating agent such as chlorambucil and bendamustine develop mostly bacterial infections $[3,4]$. Purine analogs (e.g. fludarabine) can increase the incidence of infections, but also can change the spectrum of infectious complications by increasing the number of viral and opportunistic infections. These infections can be caused by profound and prolonged depletion of CD $4+\mathrm{T}$ cells due to purine analogues [2]. The risk of infection after the addition of rituximab (anti-CD20 monoclonal antibody) to the chemotherapy is not changed significantly $[5,6]$. Infectious complications induced by alemtuzumab (anti-CD52 monoclonal antibody) can be attributed to its effect on the B and T cell depletion, as well as NK cells and monocytes depletion. Bacterial infections are responsible for $20 \%$ of all infectious complications. However, viral infections dominate by the treatment. Their incidence 
is between $20-30 \%, 2 / 3$ of all viral infections are cytomegalovirus infections (CMV) $[7,8]$. Additional opportunistic infections occurring during treatment with alemtuzumab include Pneumocystis jirovecii pneumonia (PJP), invasive fungal infections (IFIs), infections caused by mycobacteria [7-9]. Anti-CD20 monoclonal antibodies are part of the standard chemoimmunotherapy combination in the treatment of CLL patients at the first line and relapse in combination with alkylating agents and purine analogs. Besides rituximab also newer antiCD20 antibodies ofatumumab and obinutuzumab are currently approved by European Medicines Agency for use in the first-line treatment in elderly comorbid patients with CLL in combination with chlorambucil (ofatumumab can be used also in combination with bendamustine in first line). Prior studies indicate that these monoclonal antibodies do not alter the spectrum of infections [10-13]. During the last two years, the range of treatment options was expanded in use of drugs affecting signaling pathway of B-cell receptor (BCR), so-called BCR inhibitors. Ibrutinib is a molecule that inhibits the Bruton's tyrosine kinase (BTK) and induces the apoptosis of CLL cells. Idelalisib is the selective inhibitor of phosphatidylinositol-3-kinase delta (PI3K $\delta$ ). Both, ibrutinib as a single agent and idelalisib in combination with rituximab, are approved since 2014 in the treatment of patients with relapsed / refractory CLL (R/R CLL) who received at least one prior treatment and in patients with del17p in the front line. Infections were observed mainly in the first year of administration and they were reduced with duration of administration of ibrutinib in the group of patients with R / R CLL. Infections grade $\geq 3$ are decreased (36\% in $1^{\text {st }}$ year, $32 \%$ in $2^{\text {nd }}$ year, $24 \%$ in $3^{\text {rd }}$ year) [14]. There are a few causes of decreased morbidity during chronic administration of ibrutinib. One of them may be an early response to treatment and control of disease, the reduction of immunosuppressive $\mathrm{T}$ cells and also the immunomodulatory potential of ibrutinib through inhibition of ITK (interleukin2-induced T-cell kinase [15]. Another observation is that during treatment of ibrutinib there is a partial reconstitution of normal B cells and thereby humoral immunity, which was reflected in raised levels of IgA during treatment [16]. During the treatment with idelalisib plus rituximab in previously treated CLL patients, serious adverse events $\geq 3$ degree occurred in $40 \%$ cases (6 \% pneumonia, $4 \%$ sepsis, $3 \%$ diarrhea, 3\% Pneumocystis jirovecii pneumonia) [17]. The aim of this study is to evaluate the incidence of infectious complications in patients with CLL treated in one center according to the type and duration of treatment.

\section{Patients and methods}

We retrospectively evaluated the infectious complications in patients treated for chronic lymphocytic leukemia at our institution in years 2004-2016. We collected demographic data - age, sex, associated diseases included in the CIRS comorbidity score (Cumulative Illness Rating Scale), characteristics of the underlying disease - stage, cytogenetic changes (Table 1).
We evaluated infection complications in 110 patients, the average age of all enrolled patients was 61.7 years (range 34.5-91.9), 74 of them (67.27\%) were younger than 65 years. CIRS comorbidity score for all patients was 5 (range 0-13). At the time of diagnosis, the most of the patients were in the stage Rai I (60\%), together $12.73 \%$ in the stage Rai III-IV. As for cytogenetic risk factors, the majority of patients present del 13q (57.27\%). Del 17p / TP53 mutation arose also by clonal evolution during patient follow-up, this unfavorable chromosomal aberration was present in 20 patients (18.18\%). Sixty-two patients received in the first line fludarabine (FC or FCR), 26 patients bendamustine regimen (BR, bendamustine + rituximab). FCR (fludarabine, cyclophosphamide, rituximab) was used the most commonly in all lines (58 times),

Table 1. Characteristics of the study group

\begin{tabular}{|c|c|c|}
\hline & $\mathrm{N}=110$ & $\%$ \\
\hline \multicolumn{3}{|l|}{ Gender } \\
\hline Female & 29 & $26.36 \%$ \\
\hline Male & 81 & $73.64 \%$ \\
\hline \multicolumn{3}{|l|}{ Age } \\
\hline$<65 y$ & 74 & $67.27 \%$ \\
\hline$\geq 65 y$ & 36 & $32.72 \%$ \\
\hline \multicolumn{3}{|l|}{ Median 61.7y (34.5-91.9) } \\
\hline \multicolumn{3}{|l|}{ CIRS median 5 (0-13) } \\
\hline Cardiac disease & 31 & $28.18 \%$ \\
\hline Arterial hypertension & 64 & $58.18 \%$ \\
\hline Vascular disease & 16 & $14.55 \%$ \\
\hline Respiratory disease & 13 & $11.82 \%$ \\
\hline ORL disease & 6 & $5.45 \%$ \\
\hline GIT disease & 23 & $20.90 \%$ \\
\hline Hepatobiliary tract disease & 25 & $22.73 \%$ \\
\hline Urinary tract disease & 42 & $38.18 \%$ \\
\hline Musculoskeletal system disease & 14 & $12.73 \%$ \\
\hline Neurological disease & 7 & $6.36 \%$ \\
\hline Diabetes mellitus & 28 & $25.45 \%$ \\
\hline Psychiatric illness & 6 & $5.45 \%$ \\
\hline \multicolumn{3}{|l|}{ Stage Rai } \\
\hline 0 & 14 & $12.73 \%$ \\
\hline I & 66 & $60.00 \%$ \\
\hline II & 16 & $14.55 \%$ \\
\hline III & 4 & $3.64 \%$ \\
\hline IV & 10 & $9.09 \%$ \\
\hline \multicolumn{3}{|l|}{ Cytogenetic aberrations ${ }^{*}$} \\
\hline None & 11 & $10.00 \%$ \\
\hline del 13q & 63 & $57.27 \%$ \\
\hline $\operatorname{tris} 12$ & 14 & $12.73 \%$ \\
\hline del 11q(del ATM) & 42 & $38.18 \%$ \\
\hline del 17p (del p53) & 20 & $18.18 \%$ \\
\hline $\begin{array}{l}\text { Mutational status IgVH - Non- } \\
\text { mutated }\end{array}$ & 8 & $7.27 \%$ \\
\hline
\end{tabular}

Abbreviations: GIT - gastrointestinal tract, CIRS - Cumulative Illness Rating Scale, CLL- chronic lymphocytic leukemia. ${ }^{*} 38$ patients had two genetic mutations and 6 patients had 3 genetic aberrations 


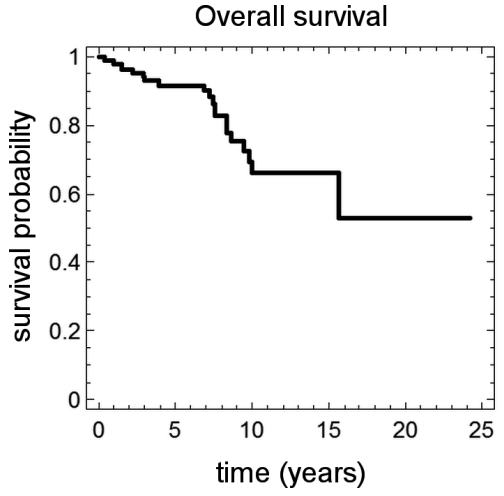

Figure 1. Overall survival of the study group

the second most commonly used mode was BR (50 times). At the period before BCR inhibitors the treatment of choice for patients with early relapse has been alemtuzumab, which was used as monotherapy or in combination (most often with corticosteroids) in 31 patients. Ofatumumab was used in 16 patients, obinutuzumab in 15 patients (in combination with FC, bendamustine or chlorambucil). Sixteen patients received ibrutinib and 2 patients recieved idelalisib in combination with rituximab (Table $\mathrm{S} 1$ in supplementary section). This study was approved by the Ethical Committee of the National Cancer Institute.

The statistical methods. Data were aggregated as the absolute number / proportion among categorical variables and the median age of the continuous variables. Used therapy regimens were divided into 7 groups of therapeutic modalities with bendamustine, fludarabine, alemtuzumab and ofatumumab (standard regimens), modes with obinutuzumab, idelalisib and ibrutinib (new regimens) and a group of other modes/modalities. We collected data according to the site of infection, type of pathogen, anti-infective treatment and severity of infections surpassed in connection with the administration of new targeted drugs, as well as standard regimens of chemoimmunoterapy. The data was tabulated as number of infectious agents according to the organ site and subsequently evaluated as a percentage of all infections, including fungal and viral infections considering the inherent mode of chemotherapy. Chi-square test and Fisher's exact test was used to compare categorical data.The relative risk was assessed as the proportion of patients with more than one infection compared to the reference group of patients with bendamustine. In evaluating line of chemotherapy the first line was reference. Overall survival was evaluated using Kaplan-Meier estimates of survival. In a multivariate analysis, we used the logistic regression model to test the dependence of the number of infections of all grades, fungal and viral by using treatment regime, in respect to the CIRS and line of therapy. P-value less than 0.05 was considered statistically significant. Used statistical software: Statgraphics Centurion XVI and MS Excel, 2010.

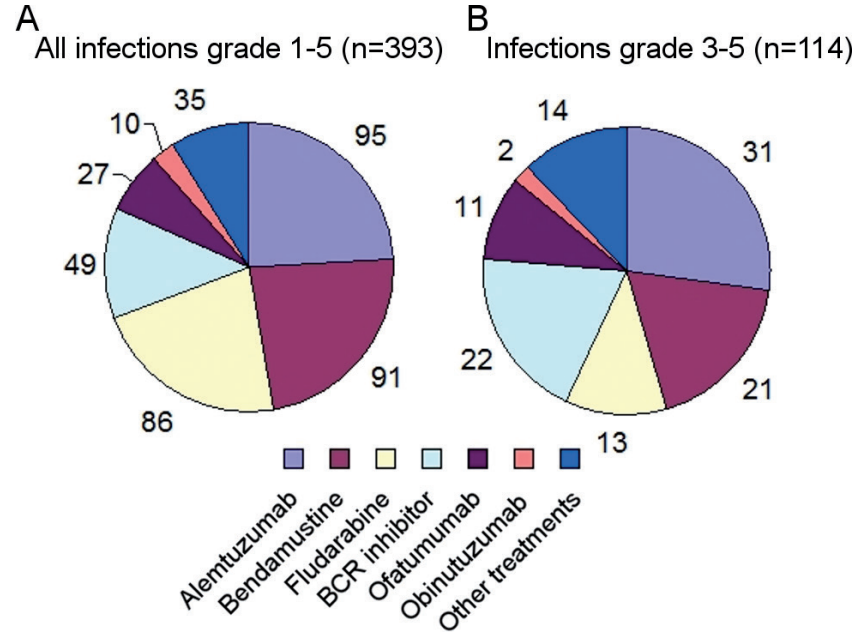

Figure 2. Number of infections by the type of treatment (A) and number of hospitalizations (B)

\section{Results}

One hundred and ten patients accumulated a total 419 person-years of follow-up ("person-years"), average 3.81 person-years. Median follow-up was 3.09 years (min 0.1 max 11.85), median survival was not reached (Figure 1). We recorded 393 episodes of infections with 114 (29.01\%) severe life threatening CTCAE grade 3-5 (27.2 per 100 personyears of follow-up) and 279 (70.99\%) infections of moderate grade 2 ( 58.23 to 100 person-years of follow-up). Figure 2 shows the number of infections by the type of treatment and number of life- threatening infections grade 3-5 requiring hospitalization according to the used treatment. Most serious infections occurred during treatment with alemtuzumab. We noted 19 deaths, 8 (7.27\%) were caused by infection, 6 patients died on the progression / transformation underlying disease $(5.45 \%)$, and 5 patients (4.54\%) died from other causes (stroke, sudden death, complications after fracture of the femur, secondary malignancy). The most common infections were the upper respiratory tract infections together with sinusitis $(45.03 \%)$, pneumonia $(26.20 \%)$, CMV reactivation occured in 32 patients (8.14\%), infections of the skin in 30 patients $(7.6 \%)$, urinary tract infections in 22 patients $(5.60 \%)$, sepsis in 14 patients $(3.56 \%)$, enterocolitis in 12 patients $(3.05 \%)$ and the other $0.8 \%$ were otitis, meningitis and cholecystitis.

Figure 3 shows the number of infections with different types of therapy which are divided by patients without infection, with one infection or more than one infection. Table 2 shows values of the infection in the modes of therapy distributed to patients without infection, with one infection or more than one infection. Most infections have occurred with the administration of monoclonal antibody alemtuzumab, these patients were at significantly higher risk of infection [RR 2.59 (1.30 to 
5.17)] than patients receiving obinutuzumab [RR 0.63 (0.48 to 0.82$)]$ ( $\mathrm{p}=0.0001)$.

Table 3 shows the spectrum of infections according to the type of treatment. In total 53 patients received bendamustine regimen. Overall 91 infections were observed. Thirty-seven patients $(69.81 \%)$ received cotrimoxazole prophylaxis and 45 patients (84.91\%) antiviral drugs (acyclovir, valacyclovir). The majority of infections were bacterial $(58.24 \%), 4.4 \%$ of viral and $7.69 \%$ of fungal were observed. One patient had Pneumocystis jirovecii infection (1.1\%). The most frequent infections were infections of upper respiratory tract (41 cases) and pneumonia (24 cases). They required 21 hospitalizations (i.e. CTCAE grade 3-5 infection). One patient died due to pneumonia caused by Pseudomonas aeruginosa combined with proven pulmonary aspergillosis.

A total of 78 patients were treated with fludarabine. All patients received antibiotic prophylaxis cotrimoxazole or pentamidine, 59 patients (84.91\%) antiviral drugs. Out of 86 infections there were $61.62 \%$ of bacterial etiology, $15.11 \%$ of viral and $8.13 \%$ of fungal infections, $12.79 \%$ were mixed

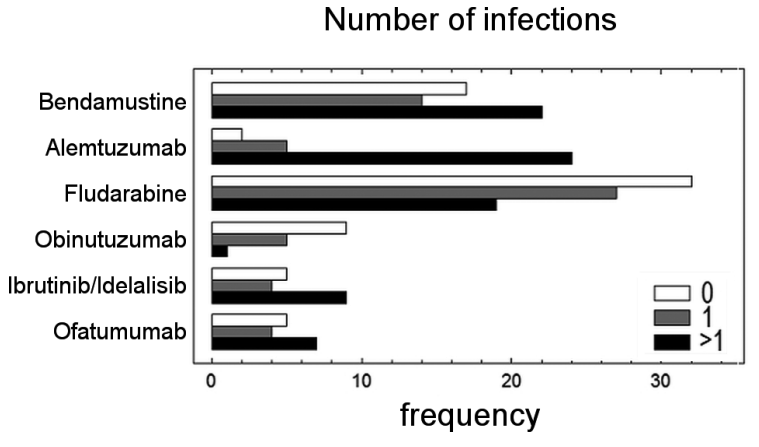

Figure 3. The number of infections with different types of therapy

bacterial-fungal. The most frequent infections were upper respiratory tract infections and sinusitis $(56.97 \%)$, followed by skin infections $(20.93 \%)$, of which $13.95 \%$ of herpes zoster infection was recorded. One patient died due to infectious complication (pneumonia of combined etiology bacterial +

Table 2. The number of infections induced by different types of therapy

\begin{tabular}{|c|c|c|c|c|}
\hline & 0 infection & linfection & More than 1 infection & Relative risk (95\% CI) \\
\hline bendamustine & $17(32.08 \%)$ & $14(26.42 \%)$ & $22(41.51 \%)$ & - \\
\hline alemtuzumab & $2(6.45 \%)$ & $5(16.13 \%)$ & $24(77.42 \%)$ & $2.59(1.30-5.17)^{\star}$ \\
\hline fludarabine & $32(41.03 \%)$ & $27(34.62 \%)$ & $19(24.36 \%)$ & $0.77(0.60-1.01)$ \\
\hline obinutuzumab & $9(60.00 \%)$ & $5(33.33 \%)$ & $1(6.67 \%)$ & $0.63(0.48-0.82)^{*}$ \\
\hline ibrutinib, idelalisib & $5(27.78 \%)$ & $4(22.22 \%)$ & $9(50.00 \%)$ & $1.17(0.70-1.96)$ \\
\hline ofatumumab & $5(31.25 \%)$ & $4(25.00 \%)$ & $7(43.75 \%)$ & $1.04(0.64-1.69)$ \\
\hline Total & 70 & 59 & 82 & - \\
\hline
\end{tabular}

Patients receiving obinutuzumab were at significantly lower risk of infection than patients treated with alemtuzumab $(p=0.0001)$, obinutuzumab $R R$ 0.63 (0.48 to 0.82 ) and alemtuzumab 2.59 (1.30 to 5.17 ).

The result was confirmed by multivariate model with respect to CIRS, line of therapy, effects of therapy and present hypogammaglulinemia, $\mathrm{p}=0.0003$, obinutuzumab RR 0.10 (0.01 to 0.99 ), alemtuzumab RR 3.76 (0.97 to 14.57 ).

Table 3. Overview of the spectrum of infections according to the different treatment type

\begin{tabular}{|c|c|c|c|c|c|c|c|c|c|c|c|c|}
\hline \multirow[b]{2}{*}{ Infection } & \multicolumn{2}{|c|}{ bendamustine } & \multicolumn{2}{|c|}{ fludarabine } & \multicolumn{2}{|c|}{ alemtuzumab } & \multicolumn{2}{|c|}{ ofatumumab } & \multicolumn{2}{|c|}{ obinutuzumab } & \multicolumn{2}{|c|}{ BCR inhibitor } \\
\hline & $\mathbf{n}$ & $\%$ & $\mathbf{n}$ & $\%$ & n & $\%$ & $\mathbf{n}$ & $\%$ & $\mathbf{n}$ & $\%$ & $\mathbf{n}$ & $\%$ \\
\hline Bacterial & 53 & 58.24 & 53 & 61.62 & 43 & 45.26 & 13 & 48.15 & 8 & 80 & 32 & 65.31 \\
\hline Combined bacterial & 5 & 5.49 & & & 3 & 3.16 & 2 & 7.41 & 2 & 20 & 2 & 4.08 \\
\hline Viral & 4 & 4.40 & 13 & 15.11 & 24 & 25.26 & 2 & 7.41 & & & 1 & 2.04 \\
\hline Fungal & 7 & 7.69 & 7 & 8.13 & 5 & 5.26 & 2 & 7.41 & & & 4 & 8.16 \\
\hline Parasitic & 0 & 0.00 & & & & & 0 & & & & 1 & 2.04 \\
\hline Pneumocystis & & & & & 1 & 1.05 & & & & & & \\
\hline Bacterial+viral & 1 & 1.10 & & & 2 & 2.11 & 2 & 7.41 & & & 1 & 2.04 \\
\hline Bacterial+fungal & 18 & 19.78 & 11 & 12.79 & 12 & 12.63 & 6 & 22.22 & & & 7 & 14.29 \\
\hline Bacterial+fungal+viral & 2 & 2.20 & 1 & 1.16 & 1 & 1.05 & & & & & & \\
\hline Bacterial+ pneumocystis+viral & 1 & 1.10 & & & & & & & & & & \\
\hline Fungal+viral & & & & & 1 & 1.05 & & & & & 1 & 2.04 \\
\hline Fungal+ pneumocystis & & & & & 2 & 2.11 & & & & & & \\
\hline Mycobacterium & & & 1 & 1.16 & 1 & 1.05 & & & & & & \\
\hline Total & 91 & 100.0 & 86 & 100.0 & 95 & 100.0 & 27 & 100.0 & 10 & 100.0 & 49 & 100.0 \\
\hline
\end{tabular}




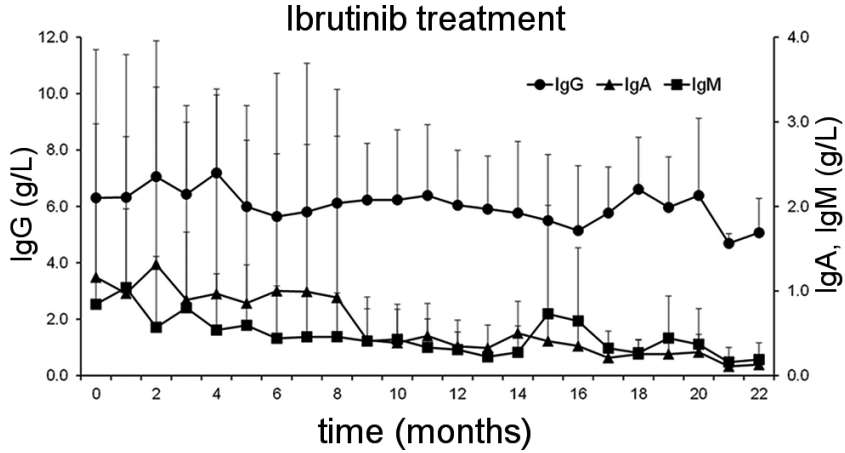

Figure 4. The average value of immunoglobulins in the treatment of ibrutinib

invasive pulmonary mycosis). Serious infections included one meningitis that has developed over the middle ear otitis (agent Pneumococcus). In one case pulmonary tuberculosis was captured (by PCR method of bronchopulmonary lavage).

A regimen with alemtuzumab was admiministered to 31 patients, who suffered from 95 infections. All patients received cotrimoxazole prophylaxis or pentamidine and antivirals (acyclovir / valacyclovir), 26 patients (83.87\%) received prophylaxis with fluconazole. There were $45.26 \%$ of bacterial infections, $25.26 \%$ of viral, $5.26 \%$ of fungal, $12.63 \%$ of mixed bacterial-fungal, 3.1\% of Pneumocystis jiroveci pneumonia, $1.05 \%$ of Mycobacterium tuberculosis. CMV viremia was identified in 23 patients (24.21\%) and pneumonia caused by influenza virus $\mathrm{H} 1 \mathrm{~N} 1$ in one patient. They required 31 hospitalizations (CTCAE grade 3-5 infections) and three patients died due to infectious complications, two due to septic shock and one patient due to pneumonia. One septic patient died in connection with fulminant course of bacterium Nocardia farcinica infection.

A total of 16 patients were treated with ofatumumab. Twelve patients $(75.00 \%)$ received cotrimoxazole prophylaxis or pentamidine, 11 patients $(68.75 \%)$ received acyclovir. Out of 27 infections the majority of infections were bacterial (48.15\%) and combined bacterial-fungal (22.22\%). Eleven hospitalizations were needed and 1 patient died due to infectious complications (for combined etiology of pneumonia bacterial-fungal).

A total of 15 patients were treated with obinutuzumab. Ten patients (66.67\%) received cotrimoxazole prophylaxis and 14 patients (93.33\%) acyclovir. Only 10 infections were observed in total. In $80 \%$ cases there was a bacterial infection, which are in particular upper respiratory tract infections caused by Staphylococcus aureus, Streptococci, Enterococci, Klebsiella, Pseudomonas aeruginosa. One patient had a serious course of Listerial sepsis. Two patients required hospitalization but no patient died due to infectious complications.

A total of 16 patients were treated with ibrutinib and 2 patients with idelalisib + rituximab. Eight patients (44.44\%) received antibiotic cotrimoxazole prophylaxis, 7 patients

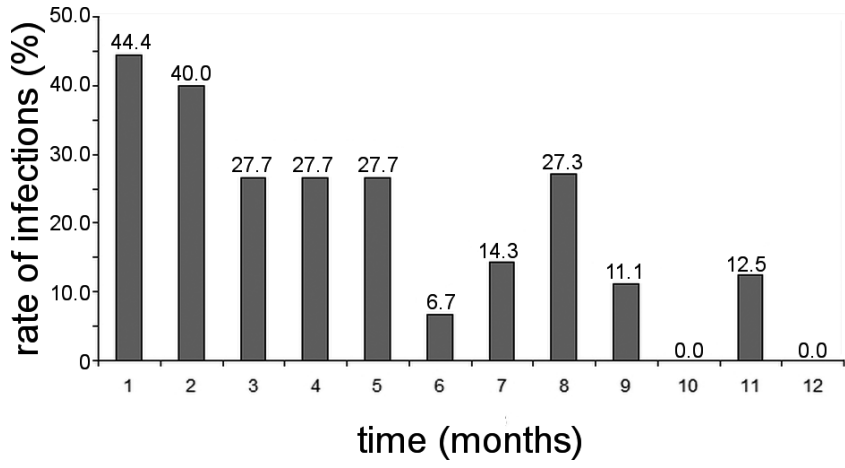

Figure 5. The number of infections during the first 12 month of treatment with ibrutinib

(38.89\%) prophylactic fluconazole and 13 patients (72.22\%) acyclovir. There were 49 infections in total, $65.31 \%$ of bacterial infections, $2 \%$ of viral, $8 \%$ of fungal, $14.2 \%$ of mixed bacterialfungal. The most common infection was an upper respiratory tract infection and pneumonia. Twenty two hospitalizations were needed. Two patients died from infectious complications. The first patient was diagnosed with pneumonia caused by multidrug strains of Pseudomonas aeruginosa, the second patient developed bilateral pneumonia of combined etiology (bacterial-invasive fungal infection). Both patients received ibrutinib in the $5^{\text {th }}$ or $6^{\text {th }}$ line of treatment, frequent recurrent infections occurred in them prior to treatment with ibrutinib. During treatment with ibrutinib, we monitored the levels of immunoglobulins. Average values of IgG, IgA, IgM had a downward trend during treatment, as can be seen from Figure 4. Figure 5 shows the reduction in the number of infections in the treatment with ibrutinib during the first 12 months.

We monitored the incidence of infections with respect to given the line of anti-leukemia therapy. Significantly higher risk of infection compared with the first line was detected in the third line ( $\mathrm{p}=0.008$, RR 1.97 (1.16 to 3.01)). Risk of viral infection was significantly higher in the third and fourth line, risk of fungal infections is shown in the 4 th and 5 th line. Bacterial infections were spaced approximately equally (Table S2 in supplementary section).

\section{Discussion}

During the last two decades the treatment of CLL has dramatically improved with the introduction of new treatment options such as purine analogs, new monoclonal antibodies and BCR signaling inhibitors, which improved the effectiveness of the treatment, but have also brought a change in the spectrum of infections. Today, we have a better knowledge about the incidence of these infections on the basis of published studies. Several recommendations regarding prevention of infections using prophylactic administration of antibiotics, antifungals, antivirals were published in the last years [1-3, 
$9,18]$. The mortality of patients with infectious complications was described in the literature in $25-50 \%$ CLL patients $[1,2]$. In our set of 110 patients 19 patients (17.2\%) died, of which $8(7.2 \%)$ due to infectious complications. Infections leading to death were pneumonia or septic shock. Depending on the type of treatment, the risk of infection was significantly higher in patients treated with alemtuzumab and the lowest risk was in the treatment with obinutuzumab. It can be explained by the fact that alemtuzumab contributed to prolonged duration of $\mathrm{T}$ and $\mathrm{B}$ cell depletion during the treatment, which lasts for months or even more than a year after the treatment [7]. Patients are most susceptible to opportunistic infections (especially viral, but also pneumocystis pneumonia, invasive fungal, or mycobacteria) despite of administration of prophylaxis during treatment and for 6 months after treatment (cotrimoxazole / pentamidine, acyclovir, fluconazole) [9]. In our study alemtuzumab was administered to high-risk patients with CLL refractory to fludarabine with chemorefractory chromosomal aberration del $17 \mathrm{p}$, in 2nd to 4th line of treatment. Most bacterial infections (45\%) were serious including sepsis, which ended in death of two patients (agens E.coli, Nocardia farcinica). The representation of opportunistic infection was similar to the previously published studies $[7,8]$. Patients had frequent viral infections (25\%), mainly reactivation of CMV viremia, and in one case pneumonia was caused by influenza virus H1N1. Preemptive treatment of CMV viremia with valganciclovir was successful in all patients. Opportunistic infection of Mycobacterium tuberculosis (1 case), pulmonary aspergillosis (15 cases) and Pneumocystis jirovecii pneumonia (3 cases) have occurred during treatment. Nowadays alemtuzumab does not have a valid registration in the EU and its use has been declined significantly also due to the fact that the new inhibitors of B-cell receptor signaling pathway are very effective in patients with unfavorable CLL after several relapses, with no response on chemoimmunotherapy or with unfavorable cytogenetic aberration (del17p / TP53 mutation). During the last 2 years we used ibrutinib in 16 patients and idelalisib only in 2 patients. Despite the short follow-up period, all achieved at least a partial remission or partial remission with lymphocytosis, none of the patients progressed. As they were heavily pre-treated patients, we observed in $50 \%$ patients more than one infection, in the most cases it was bacterial infection (65\%), viral infection in only one case. The most commonly observed infection was pneumonia (22 cases). It is very important to say, we observed a reduction of infectious complications during administration ibrutinib in the first year, which is related to the gradual improvement of parameters of blood count (neutrophil segments increased in peripheral blood). According to literature data the level of immunoglobulin IgA should increase during treatment [16]. However this claim has not been confirmed. All of the immunoglobulins IgG, IgA and IgM have tended to decrease. Immunoglobulins were substituted in patients with recurrent bacterial infections, on the other side we stopped prophylaxis (cotrimoxazole, acyclovir) in those patients who achieved a response and had no recurrent infections. Idelalisib with rituximab was used only in 2 patients, one of them had the recurrent pneumonia caused by resistant strains of Pseudomonas aeruginosa. Both patient received prophylaxis with cotrimoxazole and acyclovir and were monitored for reactivation of CMV viremia. In our study ibrutinib had very favorable safety profile. The use of ibrutinib in earlier lines of treatment could allow to prevent severe opportunistic infections. This statement shall be verified in a larger group of patients with a longer follow-up.

Our study confirmed the published data on the incidence of infections during administration of alkylating agents, purine analogs and antiCD20 monoclonal antibodies [4-6, 10-13].

Bendamustine is an alkylating agent with unique activity effective in treating patients with CLL, the efficiency is increased by combined treatment with rituximab (BR), it has a good safety profile, which we confirmed in the study. During treatment with bendamustine haematological toxicity, mostly neutropenia occured. Prophylaxis is not clearly indicated, not all patients received it, especially if they had normal levels of immunoglobulins and they were treated in the first line. Despite the lower frequency of serious opportunistic infections in the treatment with bendamustine, caution is required especially in elderly patients who have early onset neutropenia and comorbidity. These patients should receive the prophylaxis with cotrimoxazole and acyclovir.

Purine analogs such as fludarabine have been used in the treatment of CLL since the late 90s of the 20th century, so in our group it was the most frequently used mode. The purine analogues are known to cause prolonged suppression of CD4 + T lymphocytes, secondary neutropenia, which results in increased frequency of infections, including opportunistic ones.

Table 4. Infections according to the different type of treatment

\begin{tabular}{ll}
\hline Treatment & Infections \\
\hline $\begin{array}{l}\text { Alkylating agents (bendamustine) } \\
\text { Purine analogs (fludarabine) }\end{array}$ & Common bacterial pathogens, rarely opportunistic infection \\
Alemtuzumab & Viral infections, particularly CMV, opportunistic infections (yeast, filamentous fungi, pneumocystis), mycobacteriosis, \\
Ofatumumab & including rare bacterial \\
Obinutuzumab & Does not alter the spectrum of infections, caution in pretreated patients with secondary immunodeficiency \\
BCR signaling inhibitors & No change in spectrum of infections \\
\hline
\end{tabular}


All patients should receive prophylaxis with cotrimoxazole or pentamidine (in patients with allergy to cotrimoxazole) and antiviral acyclovir during treatment and 3-6 months after treatment [18]. Antifungal prophylaxis is not currently indicated, only in selected patients at secondary prophylaxis. During treatment with fludarabine particularly bacterial infections $(61.62 \%)$ were recorded, we noticed an increased incidence of viral infections (15.0\%) and $20.9 \%$ of fungal infections. If the fludarabine was used in the first-line of treatment in patients without significant comorbidities, with normal renal parameters and with recommended prophylaxis, it was safe and infectious complications were manageable.

As for the new antiCD20 monoclonal antibodies, they do not alter the spectrum of infectious complications. If they were used in the first-line of treatment, their safety profile was favorable. Obinutuzumab used in the first line, even when administered in combination with fludarabine or bendamustine, had the lowest incidence of infectious complications. Ofatumumab was used in 2 indications, in monotherapy for patients with refractory to fludarabine and alemtuzumab (8 patients) as well as in combination with bendamustine at first-line (4 patients) and at relapse (4 patients). Patients pre-treated with alemtuzumab who had refractory disease and progressed after ofatumumab had serious opportunistic infections. Prophylaxis in the first line is not clearly indicated, at relapse we must consider the type of prior therapies, neutropenia and immunoglobulin levels. We decided also according to chemotherapeutic agents used in combination with monoclonal antibodies.

According to the literature data and the results of the study the most often infections and agents are shown in Table 4 sorted by type of treatment.

Conclusions. Our study confirmed that the most toxic in terms of infections was alemtuzumab. Inhibitors of BCRsignaling pathway were highly effective and of mild toxicity. They induced a deep and long-term remission even in patients with del 17p and TP53 mutations. Especially ibrutinib had a good safety profile even the risk of infection was decreased during administration.

Although chronic lymphocytic leukemia remains currently incurable disease, new drugs have contributed to improve survival of patients with CLL. However patients are at risk of lifelong infectious complications due to secondary immune disorder resulting from the underlying disease that worsens during treatment. Patients can receive prophylactic antimicrobial therapy or substitution by intravenous immunoglobulins in prevention of infections, but active monitoring, early detection and aggressive management of each infection is very important.

Supplementary information is available in the online version of the paper.

Acknowledgments: This work was partially supported by a research grant from the Ministry of Education VEGA 1/0906/14.

\section{References}

[1] HAMBLIN AD, HAMBLIN TJ. The immunodeficiency of chronic lymphocytic leukemia. Br Med Bull 2008; 87: 49-62. https://doi.org/10.1093/bmb/ldn034

[2] MORRISON VA. Management of Infectious Complications in Patients with chronic lymphocytic leukemia. ASH education book 2007; 2007: 332-338. https://doi.org/10.1182/asheducation-2007.1.332

[3] Nosari A. Infectious Complications in Chronic Lymphocytic Leukemia. Mediterr J Hematol Infect Dis 2012; 4: e2012070. https://doi.org/10.4084/mjhid.2012.070

[4] FISCHER K, CRAMER P, BUSCH R, STILGENBAUER S, BAHLO J et al. Bendamustine combined with rituximab in patients with relapsed and/or refractory chronic lymphocytic leukemia: a multicenter phase II trial of the German Chronic Lymphocytic Leukemia Study Group. J Clin Oncol 2011; 26: 3559-3566. https://doi.org/10.1200/JCO.2010.33.8061

[5] HALLEK M, FISCHER K, FINGERLE-ROWSON G, FINK AM, BUSCH R. Addition of rituximab to fludarabine and cyclophosphamide in patients with chronic lymphocytic leukemia: a randomized, open-label, phase 3 trial. Lancet 2010; 376: 1164-1174. https://doi.org/10.1016/S01406736(10)61381-5

[6] Robak T, MOISEEV SI,DMOSZYNSKA A,SOLAL-CELIGNY P, WARZOCHA K et al. Rituximab, fludarabine and cyclophosphamide (R-FC) prolongs progression free survival in relapsed or refractory chronic lymphocytic leukemia (CLL) compared with FC alone: Final results from international randomized phase III REACH trial. Blood 2008; 112: Iba-1.

[7] KEATING MJ, FLINN I, JAIN V, BINET JL, HILLMEN $\mathrm{P}$ et al. Therapeutic role of alemtuzumab (Campath-1H) in patients who have failed fludarabine: results of a large international study. Blood 2002; 99: 3554-3561. https://doi. org/10.1182/blood.V99.10.3554

[8] HILlMEN P, SKOTNICKI AB, ROBAK T, JAKSIC B, DMOSZYNSKA A et al. Alemtuzumab compared with chlorambucil as first-line therapy for chronic lymphocytic leukemia. J Clin Oncol 2007; 25: 5616-5623. https://doi. org/10.1200/JCO.2007.12.9098

[9] OSTERBORG A, FOA R, BEZARES RF, DEARDEN C, DYER MJ et al. Management guidelines for the use of alemtuzumab in chronic lymphocytic leukemia. Leukemia 2009; 23: 1980-1988. https://doi.org/10.1038/leu.2009.146

[10] HILLMEN P, ROBAK T, JANSSENS A, BABU KG, KLOCZKO $\mathrm{J}$ et al. Chlorambucil plus ofatumumab versus chlorambucil alone in previously untreated patients with chronic lymphocytic leukemia (CEMPLEMENT 1): a randomised, multicentre, open-label phase 3 trial. Lancet 2015; 385: 1873-1883. https://doi.org/10.1016/S0140-6736(15)60027-7

[11] OFFNER F, PANAYIOTIDIS P, AFANASYEV B, JANSSEN A, GROSICKI S. Ofatumumab and bendamustine combination therapy in patients with untreated and relapsed chronic lymphocytic leukemia: initial results of the phase II study OMB115991. XV iwCLL Abstracts 2013 4.29.

[12] FLINN IW, PANAYIOTIDIS P, AFANASYEV B, JANSSEN A, GROSICKI S et al. A phase 2, multicenter study investigating 
ofatumumab and bendamustin combination in patients with utreated or relapsed CLL. Am J Hematol 2016; 91: 900-906. https://doi.org/10.1002/ajh.24430

[13] GOEDE V, FISCHER K, BUSCH R, ENGELKE A, EICHHORST B et al. Obinutuzumab plus Chlorambucil in Patients with CLL and Coexisting Conditions. N Engl J Med 2014; 370:1101-1110. https://doi.org/10.1056/NEJMoa1313984

[14] BYRD JC, FURMAN RR, COUTRE SE, BURGER IA, BLUM KA et al. Three-year follow-up of treatment-naive and previously treated patients with CLL and SLL recieving signgle-agent ibrutinib. Blood 2015; 125: 2497-2506. https:// doi.org/10.1182/blood-2014-10-606038

[15] DUBOVSKY JA, BECKWITH KA, NATARAJAN G, WOYACH J, JAGLOWSKI $S$ et al. Ibrutinib is an irreversible molecular inhibitor of ITK driving a Th1-selective pressure in T lymphocytes. Blood 2013; 122: 2539-2549. https://doi. org/10.1182/blood-2013-06-507947

[16] SUN C, TIAN X, LEE S, GUNTI S, LIPSKY S et al. Partial reconstitution of humoral immunity and fewer infections in patients with chronic lymphocytic leukemia treated with ibrutinib. Blood 2015; 126: 2213-2219. https://doi.org/10.1182/ blood-2015-04-639203

[17] Furman R, SHARMAN JP, COUTRE SE, CHESON BD, PAGEL JM et al. Idelalisib and rituximab in relapsed chronic lymphocytic leukemia, N Engl J Med 2014, 370: 997-1007. https://doi.org/10.1056/NEJMoa1315226

[18] STILGENBAUER S, FURMAN RR, ZENT CS. Management of chronic lymphocytic leukemia. Am Soc Clin Oncol Educ Book 2015: 164-175. https://doi.org/10.14694/EdBook AM.2015.35.164 
Table S1. Treatment in each line of therapy (to be included in supplementary section)

\begin{tabular}{|c|c|c|c|c|c|c|c|c|}
\hline Treatment/Line & I & II & III & IV & $\mathbf{V}$ & VI & VII & sum \\
\hline \multicolumn{9}{|c|}{ Standard regimens } \\
\hline with fludarabine, subtotal & & & & & & & & 78 \\
\hline & 15 & & 1 & & & & & 16 \\
\hline $\mathrm{FCM}+\mathrm{R}$ & & 2 & & & & & & 2 \\
\hline $\mathrm{FC}+\mathrm{R}$ & 47 & 9 & 1 & & & 1 & & 58 \\
\hline OFAR & & 1 & & & & & 1 & 2 \\
\hline with bendamustine, subtotal & & & & & & & & 53 \\
\hline Bendamustine & & & & 2 & & 1 & & 3 \\
\hline $\mathrm{B}+\mathrm{R}$ & 26 & 12 & 9 & 2 & 1 & & & 50 \\
\hline Alemtuzumab, subtotal & & & & & & & & 31 \\
\hline A & 1 & 10 & 6 & 3 & & 1 & & 21 \\
\hline $\mathrm{B}+\mathrm{A}+\mathrm{MP}$ & 1 & & 1 & & & & & 2 \\
\hline $\mathrm{MP}+\mathrm{A}$ & & 1 & 4 & & 1 & & & 6 \\
\hline CFAR & & & 1 & 1 & & & & 2 \\
\hline Ofatumumab, subtotal & & & & & & & & 16 \\
\hline $\mathrm{O}$ & & & 3 & 2 & 3 & & & 8 \\
\hline $\mathrm{O}+\mathrm{B}$ & 4 & & & 1 & 3 & & & 8 \\
\hline \multicolumn{9}{|c|}{ Other regimens } \\
\hline $\mathrm{R}$ & & 3 & 1 & & & & & 4 \\
\hline $\mathrm{MP}+\mathrm{R}$ & & 1 & & & & & & 1 \\
\hline chlorambucil & 1 & & & & & & & 1 \\
\hline chlorambucil + R & 1 & & & & & & & 1 \\
\hline ICE & & & 1 & & & & & 1 \\
\hline $\mathrm{R}-\mathrm{CVP}$ & & 1 & & & & & & 1 \\
\hline R-CHOP/R-DHAP & 1 & 1 & & 2 & & & & 4 \\
\hline $\mathrm{R}+\mathrm{VCR}+\mathrm{PDN}$ & & & & 1 & & & & 1 \\
\hline HD-MP/PDN & & & 1 & & & 1 & & 2 \\
\hline radiotherapy & & & & & 3 & & & 3 \\
\hline SCT & & 1 & 3 & 1 & & & & 5 \\
\hline \multicolumn{9}{|c|}{ New regimens } \\
\hline BCR inhibitor, subtotal & & & & & & & & 18 \\
\hline ibrutinib & 1 & 1 & 3 & 8 & 1 & 1 & 1 & 16 \\
\hline idelalisib+R & & & & & 1 & 1 & & 2 \\
\hline Obinutuzumab (G), subtotal & & & & & & & & 15 \\
\hline $\mathrm{G}+$ chlorambucil & 2 & 1 & & & & & & 3 \\
\hline $\mathrm{G}+\mathrm{FC}$ & 6 & 1 & & & & & & 7 \\
\hline $\mathrm{G}+\mathrm{B}$ & 4 & 1 & & & & & & 5 \\
\hline Total & 110 & 46 & 35 & 23 & 13 & 6 & 2 & 235 \\
\hline
\end{tabular}

Abbreviations: F-fludarabine, C-cyclophosphamide, M-mitoxantrone, R-rituximab, A-alemtuzumab, B-bendamustine, MP-methylprednisolone, O-ofatumumab , G-obinutuzumab, VCR -vincristine, PDN-prednisone,ICE-ifosfamide,cytosine arabinoside,etoposide, CVP-cyclophosphamide, vincristine, prednisone, CHOP-cyclophosphamide,doxorubicin,vincristine,prednisone, DHAP- dexamethasone, cytosine arabinoside, cisplatin, OFAR-oxaliplatin, fludarabine, alemtuzumab, rituximab, CFARcyclophosphamide, fludarabine, alemtuzumab, rituximab, SCT-stem cell transplantation 
Table S2. The number of infections according to line of anti-leukemia treatment (to be included in supplementary section)

\begin{tabular}{|c|c|c|c|c|c|c|c|c|c|c|c|c|}
\hline Line & $\mathrm{N}$ & CIRS & $\begin{array}{c}0 \\
\text { infection }\end{array}$ & 1infection & $\begin{array}{c}\text { More than } \\
1 \\
\text { infection }\end{array}$ & $\begin{array}{l}\text { Relative } \\
\text { risk } \\
(95 \% \mathrm{CI})\end{array}$ & $\begin{array}{l}\text { Bacterial } \\
\text { infection } \geq 1\end{array}$ & $\begin{array}{c}\text { Relative } \\
\text { risk } \\
(95 \% \mathrm{CI})\end{array}$ & $\begin{array}{c}\text { Viral } \\
\text { infection } \geq 1\end{array}$ & $\begin{array}{c}\text { Relative } \\
\text { risk } \\
(95 \% \mathrm{CI})\end{array}$ & $\begin{array}{l}\text { Fungal } \\
\text { infection } \\
\geq 1\end{array}$ & $\begin{array}{c}\text { Relative } \\
\text { risk } \\
(95 \% \mathrm{CI})\end{array}$ \\
\hline I & $\begin{array}{c}107 \\
(100.00 \%)\end{array}$ & $\begin{array}{c}5 \\
(0-13)\end{array}$ & $\begin{array}{c}39 \\
36.45 \%\end{array}$ & $\begin{array}{c}38 \\
35.51 \%\end{array}$ & $\begin{array}{c}30 \\
28.04 \%\end{array}$ & - & $\begin{array}{c}60 \\
56.07 \%\end{array}$ & - & $\begin{array}{c}17 \\
15.89 \%\end{array}$ & - & $\begin{array}{c}20 \\
18.69 \%\end{array}$ & - \\
\hline II & $\begin{array}{c}\mathbf{3 9} \\
(100.00 \%)\end{array}$ & $\begin{array}{c}5 \\
(0-12)\end{array}$ & $\begin{array}{c}16 \\
41.03 \%\end{array}$ & $\begin{array}{c}7 \\
17.95 \%\end{array}$ & $\begin{array}{c}16 \\
41.03 \%\end{array}$ & $\begin{array}{c}1.46(0.84- \\
2.40)\end{array}$ & $\begin{array}{c}23 \\
58.97 \%\end{array}$ & $\begin{array}{c}1.05(0.72- \\
1.42)\end{array}$ & $\begin{array}{c}10 \\
25.64 \%\end{array}$ & $\begin{array}{c}1.61(0.73- \\
3.36)\end{array}$ & $\begin{array}{c}12 \\
30.77 \%\end{array}$ & $\begin{array}{c}1,64(0.82- \\
3.15)\end{array}$ \\
\hline III & $\begin{array}{c}\mathbf{2 9} \\
(100.00 \%)\end{array}$ & $\begin{array}{c}5 \\
(0-12)\end{array}$ & $\begin{array}{c}7 \\
24.14 \%\end{array}$ & $\begin{array}{c}6 \\
20.69 \%\end{array}$ & $\begin{array}{c}16 \\
55.17 \%\end{array}$ & $\begin{array}{c}1.97(1.16- \\
3.01)^{*}\end{array}$ & $\begin{array}{c}20 \\
68.97 \%\end{array}$ & $\begin{array}{c}1.23(0.84- \\
1.60)\end{array}$ & $\begin{array}{c}10 \\
34.48 \%\end{array}$ & $\begin{array}{c}2.17(1.00- \\
4.34)^{*}\end{array}$ & $\begin{array}{c}6 \\
20.69 \%\end{array}$ & $\begin{array}{c}1.07(0.42- \\
2.55)\end{array}$ \\
\hline IV & $\begin{array}{c}19 \\
(100.00 \%)\end{array}$ & $\begin{array}{c}4 \\
(0-11)\end{array}$ & $\begin{array}{c}2 \\
10.53 \%\end{array}$ & $\begin{array}{c}5 \\
26.32 \%\end{array}$ & $\begin{array}{c}12 \\
63.16 \%\end{array}$ & $\begin{array}{c}1.31(0.57- \\
2.47)\end{array}$ & $\begin{array}{c}15 \\
78.95 \%\end{array}$ & $\begin{array}{c}1.41(0.93- \\
1.73)\end{array}$ & $\begin{array}{c}10 \\
52.63 \%\end{array}$ & $\begin{array}{c}3.31(1.59- \\
5.89)^{*}\end{array}$ & $\begin{array}{c}9 \\
47.37 \%\end{array}$ & $\begin{array}{c}2.53(1.19- \\
4.57)^{*}\end{array}$ \\
\hline $\mathbf{V}$ & $\begin{array}{c}\mathbf{1 0} \\
(100.00 \%)\end{array}$ & $\begin{array}{c}3 \\
(0-9)\end{array}$ & $\begin{array}{c}2 \\
20.00 \%\end{array}$ & $\begin{array}{c}3 \\
30.00 \%\end{array}$ & $\begin{array}{c}5 \\
50.00 \%\end{array}$ & $\begin{array}{c}1.78(0.67- \\
3.13)\end{array}$ & $\begin{array}{c}8 \\
80.00 \%\end{array}$ & $\begin{array}{c}1.43(0.77- \\
1.77)\end{array}$ & $\begin{array}{c}0 \\
0.00 \%\end{array}$ & $0(0-2,44)$ & $\begin{array}{c}5 \\
\mathbf{5 0 . 0 0 \%}\end{array}$ & $\begin{array}{c}2.68(0.98- \\
4.94) *\end{array}$ \\
\hline VI & $\begin{array}{c}\mathbf{5} \\
(100.00 \%)\end{array}$ & $\begin{array}{c}4 \\
(1-9)\end{array}$ & $\begin{array}{c}3 \\
60.00 \%\end{array}$ & $\begin{array}{c}0 \\
0.00 \%\end{array}$ & $\begin{array}{c}2 \\
40.00 \%\end{array}$ & $\begin{array}{c}1.43(0.25- \\
3.17)\end{array}$ & $\begin{array}{c}3 \\
60.00 \%\end{array}$ & $\begin{array}{c}1.07(0.30- \\
1.70)\end{array}$ & $\begin{array}{c}1 \\
20.00 \%\end{array}$ & $\begin{array}{c}1.26(0.06- \\
5.07)\end{array}$ & $\begin{array}{c}3 \\
60.00 \%\end{array}$ & $\begin{array}{c}3.21(0.84- \\
5.40)\end{array}$ \\
\hline VII & $\begin{array}{c}\mathbf{2} \\
(100.00 \%)\end{array}$ & $\begin{array}{c}6 \\
(0-6)\end{array}$ & $\begin{array}{c}1 \\
50.00 \%\end{array}$ & $\begin{array}{c}0 \\
0.00 \%\end{array}$ & $\begin{array}{c}1 \\
50.00 \%\end{array}$ & $\begin{array}{c}1.78(0.09- \\
3.58)\end{array}$ & $\begin{array}{c}1 \\
50.00 \%\end{array}$ & $\begin{array}{c}0.89(0.05- \\
1.76)\end{array}$ & $\begin{array}{c}0 \\
0.00 \%\end{array}$ & $\begin{array}{c}1.26(0.06- \\
5.07)\end{array}$ & $\begin{array}{c}1 \\
50.00 \%\end{array}$ & $\begin{array}{c}2.68(0.14- \\
5.47)\end{array}$ \\
\hline Total & $\begin{array}{c}\mathbf{2 1 1} \\
(100.00 \%)\end{array}$ & $\begin{array}{c}5 \\
(0-13)\end{array}$ & $\begin{array}{c}\mathbf{7 0} \\
33.18 \%\end{array}$ & $\begin{array}{c}\mathbf{5 9} \\
27.96 \%\end{array}$ & $\begin{array}{c}\mathbf{8 2} \\
38.86 \%\end{array}$ & - & $\begin{array}{c}\mathbf{1 3 0} \\
61.61 \%\end{array}$ & - & $\begin{array}{c}\mathbf{4 8} \\
22.75 \%\end{array}$ & - & $\begin{array}{c}\mathbf{5 6} \\
26.54 \%\end{array}$ & - \\
\hline
\end{tabular}

